\title{
Design of Type 2 Fuzzy Logic Controller Based Inverter for Isolated PV System

\author{
${ }^{* 1}$ Raj Kumar Sahu, ${ }^{2}$ Binod Shaw \\ 1,2National Intitute of Technology, Raipur, India. \\ Email:rajkumarsao@gmail.com,binodshaw2000@gmail.com
}

Received: 16th October 2019, Accepted: 31st January 2020, Published: 30th April 2020

\begin{abstract}
In this article, a Type 2 fuzzy logic controller (T2FLC) is implemented in the PV system to improve the magnitude and frequency as well as the transient time response of the photovoltaic (PV) system. T2FLC is capable to handle more uncertainty because of the PV characteristic variable with atmospheric temperature and irradiation of the sun. Simple and most widely used Perturb \& Observation (P\& O) based MPPT technique has been implemented to extract maximum power to generate the desired switching pulse for DC-DC converter in the proposed standalone PV system. Deployed T2FLC based inverter in the proposed standalone PV system with different loads can improve the response of the system and reduce the oscillations as well as noise. The performance of the system validates over with proportional-integral (PI) and T1FLC controller. The proposed T2FLC algorithm deployed in a standalone three-phase PV system shows performance better than the other two controllers and simulate in MATLAB/SIMULINK environment.
\end{abstract}

\section{Keywords}

Fuzzy Logic Controller (FLC); Photo Voltaic System (PV); Type 2 Fuzzy Logic Controller (T2 FLC); Perturb \& Observation $(P \& O)$.

\section{Introduction}

Renewable energy sources (Solar, wind, fuel, and SHP) have dragged the attention in the last few decades to compensate for the demand for electrical energy. The adaptation of renewable energy contributes to clean, reliable and stable power with no fuel cost. Photovoltaic (PV) power generation is highly preferred among all renewable energy sources because of its benefits such as easy installation, eco-friendly power generation, less maintenance, and no noise. PV system is widely preferred to be used as off-grid and on-grid. [1] The limitation in terms of efficiency of the proposed PV cell is less and the initial installation cost very high. Irradiance and environmental temperature are two eminent factors which influence the characteristics of a PV system. [2][3][4] Many MPPT techniques suggested by the author to improve the efficiency of the PV system. [5] Many inverter control techniques have been published, the proportional-integral (PI) based inverter control widely used to improve the performance of the system. Fuzzy Logic Controller (FLC) is a popular technique there is no need for exact mathematical equations. Due to this advantage, it is easy to design the inverter controller over the traditional controller. [6][7][8] But the function of FLCs relies upon some factors like rules and membership function. In this paper, Implement the interleave type 2 fuzzy logic controller to improve the performance of a three-phase off-grid PV system validate with PI and fuzzy logic controller. [10] has depicted a strive approach by enforcing ALO optimized PID based MPPT controller. An adaptive-SOS tuned T2FPID controller is implemented in AGC. [9]

\section{Proposed Standalone PV System}

A systematic arrangement proposed standalone PV system and Simulink model has depicted in Fig.1 and Fig.2 respectively. A PV system consists of a PV array, DC-DC Boost converter, and an MPPT controller. Sahu RK and Shaw B 2017 elucidate the function of PV cells properly with the help of equation and equivalent circuit. A solar PV panel has generated a finite amount of energy but it can be increased by using MPPT techniques. Also, improve the transient time using a suitable control algorithm for the converter as well as an inverter of the PV system. Many Maximum Power Point Tracking (MPPT) techniques are used to control the switching action of the converter and improve the efficiency of the PV system. Because PV module generates nonlinear power due to variation of solar insolation level and temperature explained by Y. T Tan et al., 2004, W.D. Soto et al., 2006. In this work, Perturb and Observe algorithms are used to generate a duty cycle for the DC-DC converter, which is widely used and simple to implement. T2FLC algorithm-based controller is used to generate gate pulse for three-phase inverter switches which helps to produce distortion less and noise-free output voltage and current. 


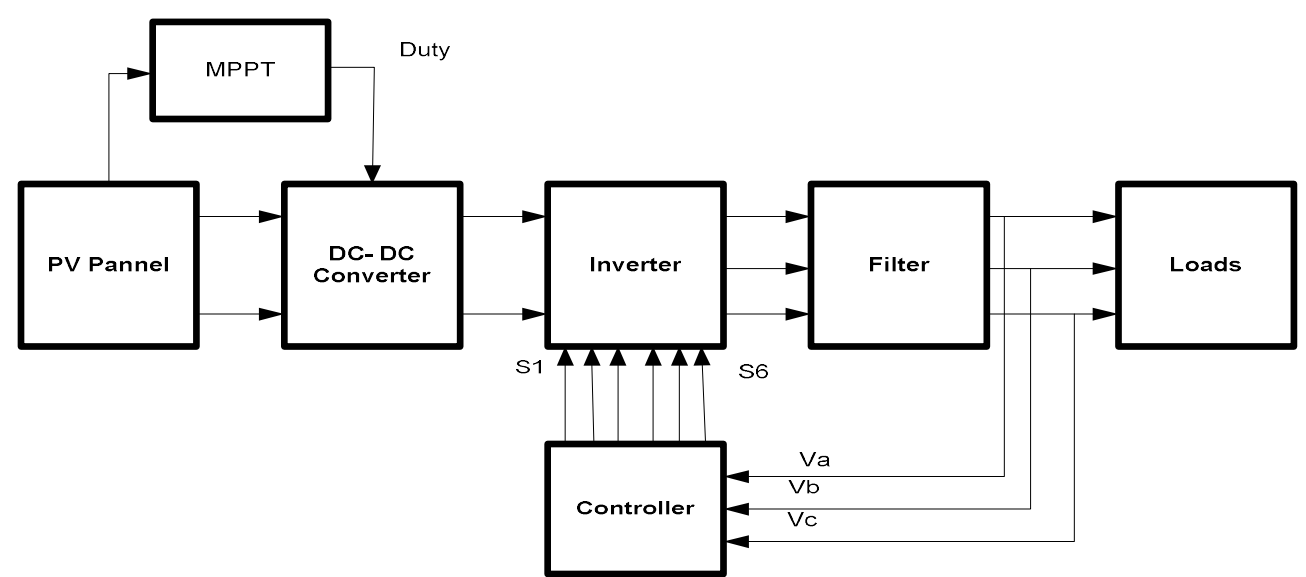

Fig.1: Proposed Standalone PV System.

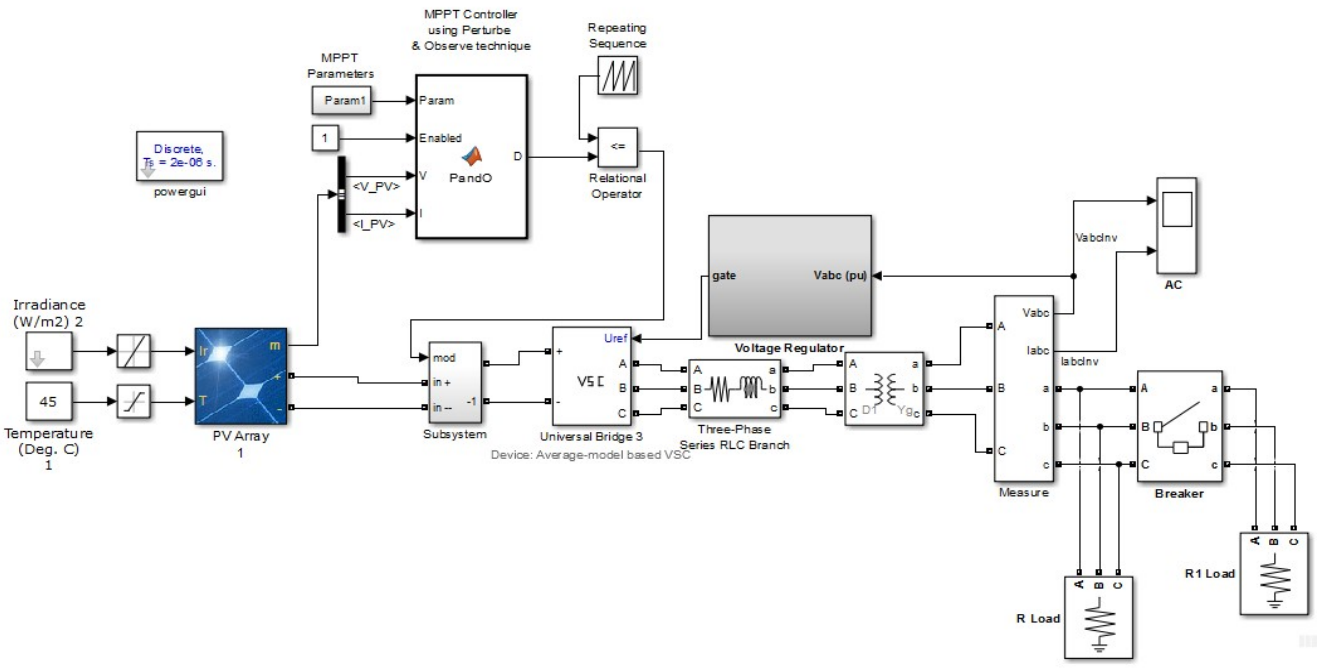

Fig.2: Simulink Model of PV System.

Type 2 Fuzzy Logic Controller

The main function of the PV inverter controller is providing load stability. Implementation of the T2FLC algorithm based inverter controller, it improves the output quality of inverter along with minimum the noise \& disturbance. [11][12] An inverter controller algorithm can reduce the disturbance in the magnitude of output voltage and frequency. In this paper, the following controller intended for an inverter is as Proportional Integral (PI) controller, T1FLC, and T2FLC Controller. Executions each of the three controllers are contrasting and examination with deference with transient time. Details Simulink and block diagram are depicted in Fig. 3 and Fig. 4 respectively. Internal working with block diagram is presented in Fig. 5. The rule adopted for T2FLC is shown in Table.1. The membership function of Type 1 fuzzy logic is a crisp value and it has two dimension memberships function whereas Type 2 fuzzy logic has three dimension membership functions. The membership function of Type 2 fuzzy logic is the union of two membership functions of Type 1 fuzzy logic called upper membership function (UMF) and lower membership function (LMF) is shown in Fig. 6. The new additional dimension of Type 2 Fuzzy logic is considered as the footprint of uncertainty. This new dimension capable of handling precisely modeling and controlling uncertainties. In Type 2 FLC, defuzzifier dived in two parts as type reduction and defuzzifier as a display in Fig. 5. 


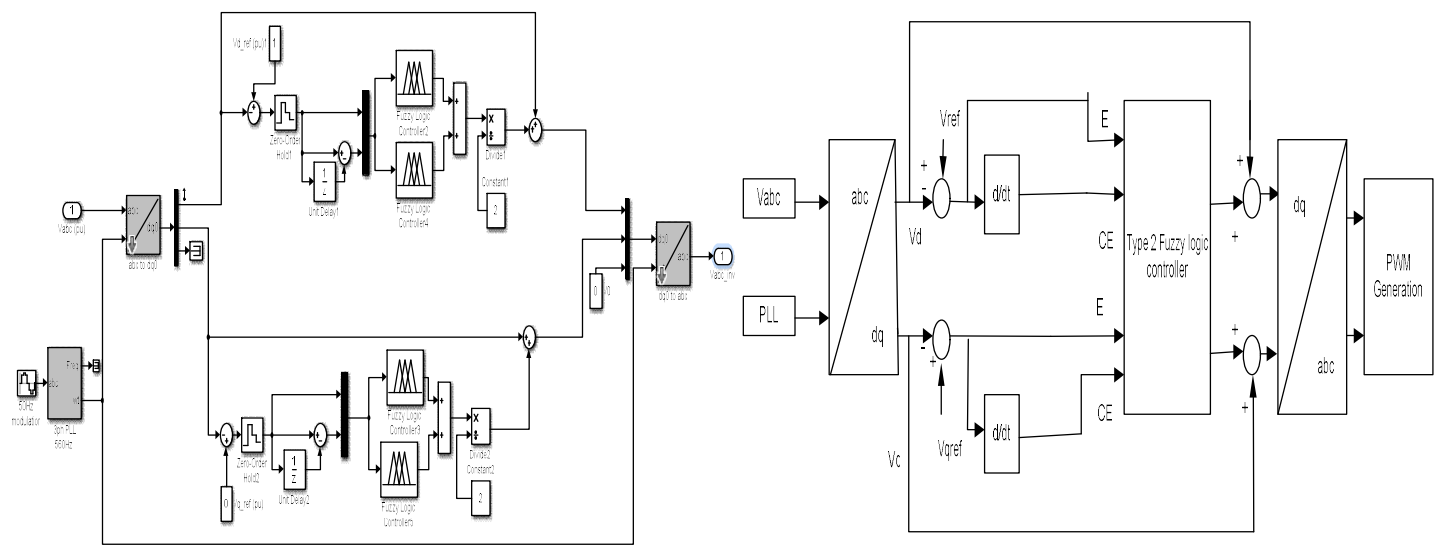

Fig. 3: Simulink Block Diagram of T2FLC.

Fig. 4: Proposed T2FLC Model.

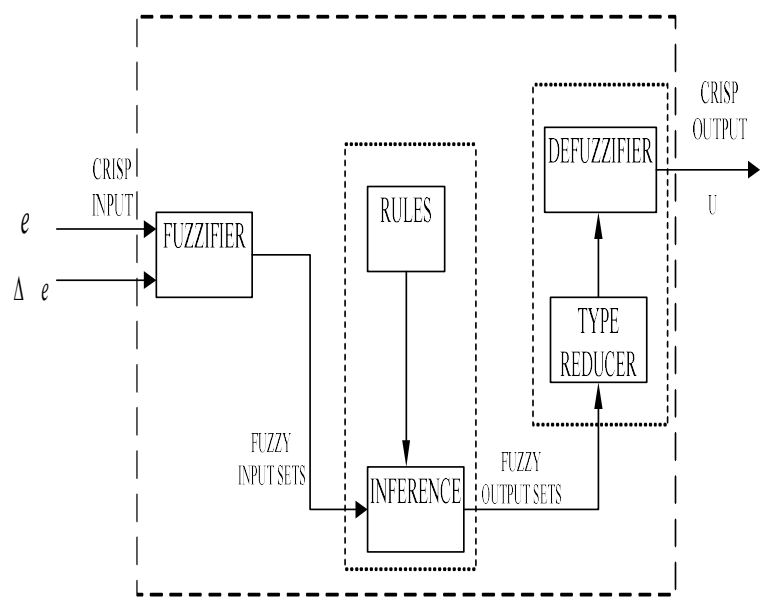

Fig. 5: Type-2 FLC Block Diagram

\begin{tabular}{|l|l|l|l|l|l|}
\hline \multirow{2}{*}{ e } & \multicolumn{5}{|c|}{$\Delta \mathrm{e}$} \\
\cline { 2 - 6 } & HN & LN & Z & LP & HP \\
\hline HN & HN & HN & LN & LN & Z \\
\hline LN & HN & LN & LN & Z & LP \\
\hline Z & LN & LN & Z & LP & LP \\
\hline LP & LN & Z & LP & LP & HP \\
\hline HP & Z & LP & HP & HP & HP \\
\hline
\end{tabular}

Table 1: Rules Adopted for Type-2 FLC 


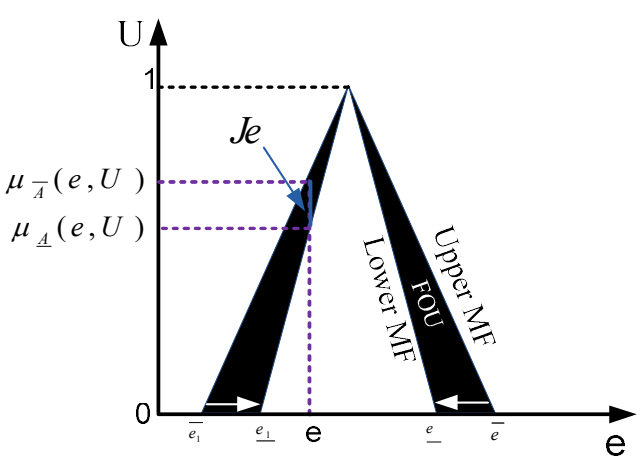

Fig. 6: Membership Function Structure of a Type-2 Fuzzy Set.

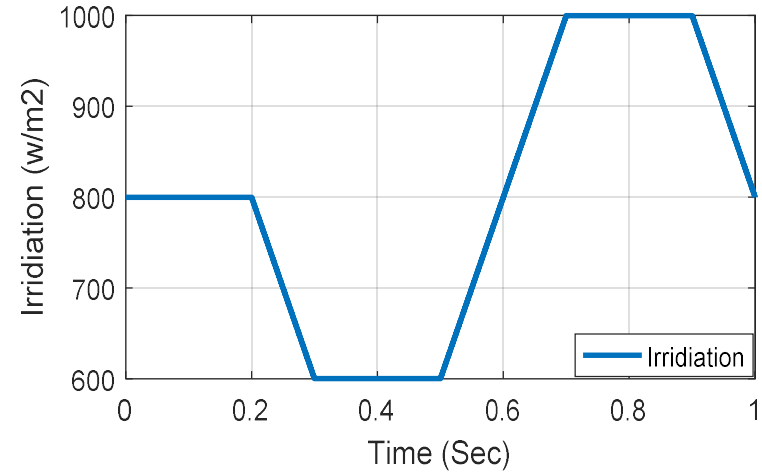

Fig 7: Solar Irradiance.

\section{Results}

The proposed algorithm will be simulating on the MATLAB platform. To validate the performance of the proposed inverter controller and simulations has validated over PI and T1FLC. Regulated DC-DC voltage is obtained using buck converter and $\mathrm{P} \& \mathrm{O}$ is used to generate the duty cycle for converter switch. T2FLC is implemented to generate a switching pulse for an inverter. Resistive load from $3 \mathrm{KW}$ to $1 \mathrm{KW}$ is changed at time 0.8 second and three-phase line power and line voltage are shown Fig.8 and Fig.9 respectively. Three-phase voltage and power in per unit and irradiation are portrayed in Fig. 10, Fig. 11 and Fig.7 respectively.

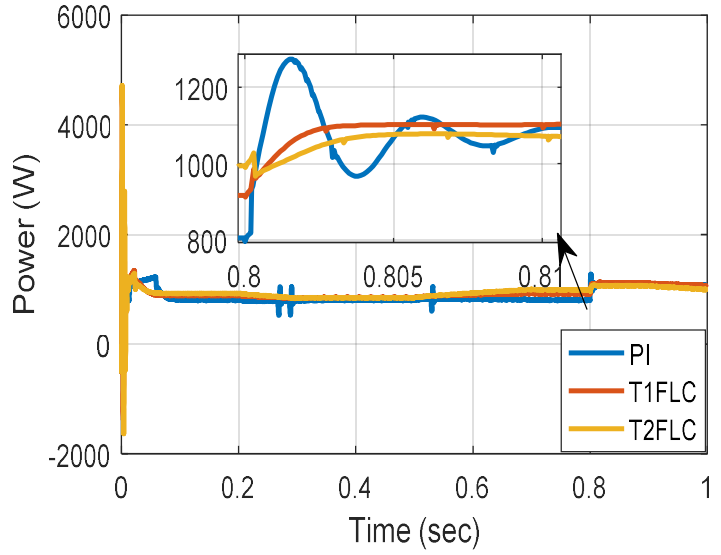

Fig. 8: Power vs Time

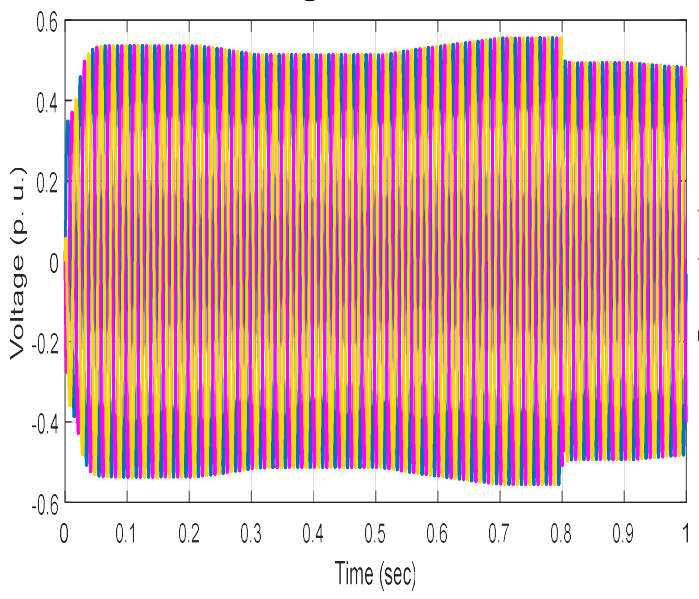

Fig. 10: Three Phase Line Voltage.

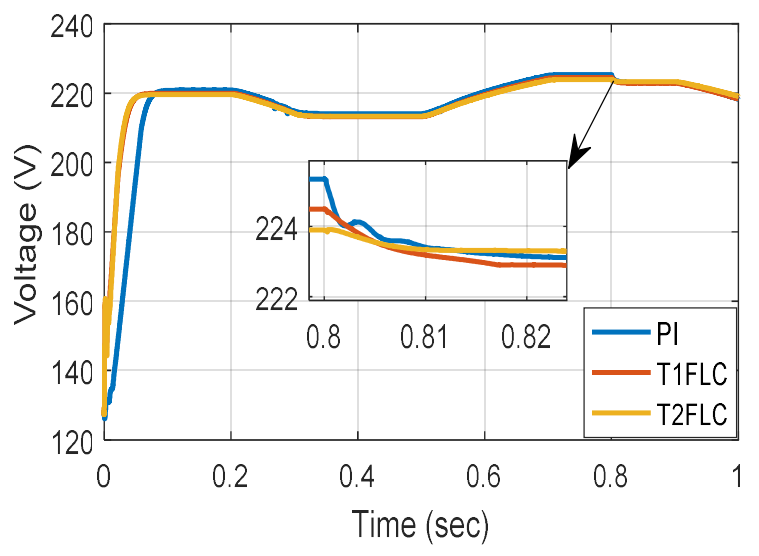

Fig. 9: Voltage vs Time

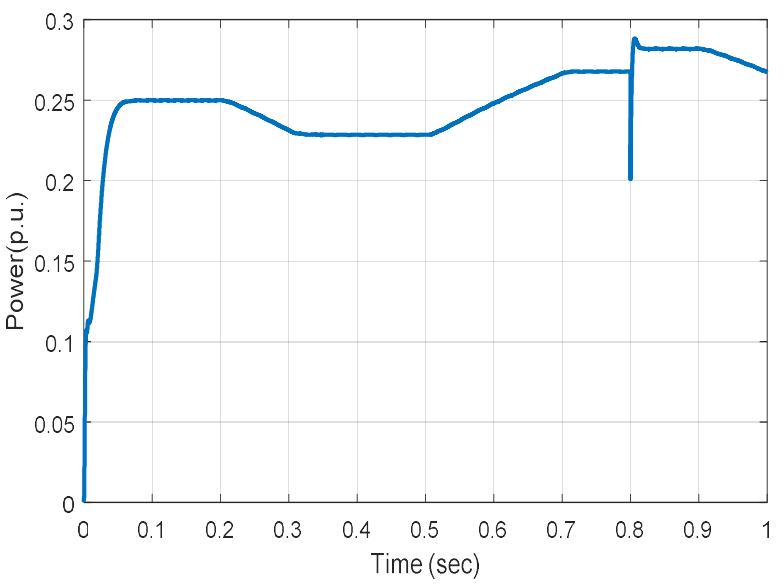

Fig. 11: Three Phase Line Power. 


\section{Conclusions}

In this paper, an inverter controller for a standalone PV system with resistive loads as shown in Fig. 1 and compares the performance of inverter controllers T2FLC, T1FLC and PI. T2FLC is capable of controlling more uncertainty than the T1FLC and PI. Error and change in error are applied to an input variable in the proposed controller and the output variable is control the switching performance. Variable irradiance is applied in the PV array. MATLAB/Simulink simulation is used to validating the performance of the system with variable irradiations. Results show that the performance of the Type 2 fuzzy logic controller better than the other two controllers. Its time response is also fast. The output of the inverter is showing better performance.

\section{References}

[1]. Blaabjerg F, Zhe C and Kjaer S B, 2004. Power electronics as efficient interface in dispersed power generation systems, IEEE Trans. Power Electron. 19(3): 1184-1194.

[2]. Tan Y. T., D. S. Kirschen, and N. Jenkins 2004. A model of PV generation suitable for stability analysis, IEEE Trans. Energy Convers., vol. 19, no. 4, pp. 748-755.

[3]. Soto W. D., S. A. Klein, and W. A. Beckman 2006. Improvement and validation of a model for photovoltaic array performance, Solar Energy, vol. 80, no. 1, pp. 78-88.

[4]. Villalva M. G., J. R. Gazoli, and E. R. Filho 2009. Comprehensive approach to modeling and simulation of photovoltaic arrays, IEEE Trans. Power Electron., vol. 24, no. 5, pp. 1198-1208.

[5]. Esram T. and P. L. Chapman, 2007. Comparison of Photovoltaic Array Maximum Power Point Tracking Techniques, IEEE Trans. Energy Convers., vol. 22, no. 2, pp. 439-449.

[6]. Letting L.K., J.L. Munda, Y. Hamam 2012. Optimization of a fuzzy logic controller for PV grid inverter control using S-function based PSO, Sol. Energy pp. 1689-1700.

[7]. Mutlag H., H. Shareef, A. Mohamed, M. A. Hannan, and J. A. Ali 2014. An Improved Fuzzy Logic Controller Design for PV Inverters Utilizing Differential Search Optimization, International Journal of Photoenergy volume 2014, Article ID 469313, 14 pages.

[8]. Shareef H., A. H. Mutlag, and A. Mohamed 2015. A novel approach for fuzzy logic PV inverter controller optimization using lightning search algorithm, Neuro computing, vol. 168, pp. 435-453.

[9]. Nayak JR, Shaw B \& Sahu BK 2017. Application of Adaptive-SOS (ASSOS) algorithm based interval type-2 fuzzy-PID controller with derivative filter for automatic generation control of an interconnected power system.

[10]. Sahu RK \& Shaw B, 2017. Design of solar system by implementing ALO optimized PID based MPPT controller, Proceedings of Recent Innovations in Electrical, Electronics \& Communication Systems, GEU, Deharadun

[11]. Mendel J.M., Q. Liang 2000. Interval type-2 fuzzy logic systems: theory and design, IEEE Trans. Fuzzy Syst. Pp. 535-550.

[12]. Castillo O. and P. Melin 2012. A review on the design and optimization of interval type-2 fuzzy controllers, Appl. Soft Comput. J., vol. 12, no. 4, pp. 1267-1278. 